\title{
Saving Lives: For the Best Outcome?
}

\author{
Xueshi Wang ${ }^{1}$
}

Received: 10 August 2020 / Revised: 15 February 2021 / Accepted: 26 February 2021 /

Published online: 26 April 2021

(C) The Author(s), under exclusive licence to Springer Nature B.V. 2021

\begin{abstract}
In this article, I critique a moral argument developed in Frances Kamm's Intricate Ethics: Rights, Responsibilities, and Permissible Harm. The argument, which I label the Best Outcome Argument, aims to criticize the Taurekian idea that it is not worse if more people die than if fewer do in conflict situations, where it is hard to distinguish individuals from one another solely by reference to the relative strength of their claims. I argue that the Best Outcome Argument is flawed for three reasons: (1) the symmetry feature defined by the impartiality principle holds only in a limited class of conflict situations; (2) individuals should be treated in a consistent way throughout the whole process of reasoning; (3) comparative evaluations gained in different contexts, at least in some cases, cannot be used in one and the same argument.
\end{abstract}

Keywords Fairness · John Taurek · The best outcome argument $\cdot$ The number problem

\section{Introduction: The Best Outcome Argument}

Consider a hypothetical choice between using a scarce ventilator to save one COVID-19 patient (A) and using it to save two other COVID-19 patients (B and C). ${ }^{1}$ Assume, as most researchers in this field do, that there are no morally relevant differences among these three patients, and there is no special tie between the physician or the health care provider charged with the task of determining the

\footnotetext{
1 A has to use the entire machine to get oxygen into the lungs and remove carbon dioxide from the body, while B and C can share the same machine for life support. The medical details as to why different individuals need a varying amount of resources is simply out of our concern. It can safely be assumed that their needs are solely determined by the nature of the physical condition and have nothing to do with diets, habits and physical exercises.
}

Xueshi Wang

xueshiwang01@gmail.com

1 Department of Philosophy, Harvard University, 25 Quincy Street, Cambridge, MA 02138, USA 
allocation of ventilation therapy and any of these three potential recipients. ${ }^{2}$ Let us call this example the Rescue Case.

Taurek (1977) argues that the agent should flip an unbiased coin to decide who is to receive the ventilation therapy. One of the reasons for using the random selection procedure is that the state consisting of the deaths of the two individuals is not worse than the state consisting of the death of the one individual. That is, it is no worse if $\mathrm{B}$ and $\mathrm{C}$ die than if A alone dies. When it comes to conflict situations of this sort where it is hard to distinguish individuals from one another solely by reference to the relative strength of their claims, as Taurek argues, numbers should not count in deciding whether to distribute the good in question to save the many or to save the few. ${ }^{3}$ Morality demands that the agent should treat everyone with equal concern and respect and thus give each individual at least an equal chance of receiving ventilation therapy. It is not surprising that Taurek's thesis has been the subject of intense criticism over the past decades. Kamm's Best Outcome Argument is one of the wellknown criticisms of Taurek's claim regarding the normative role of numbers. ${ }^{4}$

Using Pareto improvement and the impartiality principle, the Best Outcome Argument aims to deny the validity of Taurek's no-worse claim. Both principles can be formulated as follows:

\footnotetext{
${ }^{2}$ Assume further that each person, based on their reasonable needs for preserving life for a considerable period of time, has an equal claim to receiving ventilator therapy. Some philosophers, notably Broome (1990) Curtis (2014) and Piller (2017), believe that if claims cannot all be equally satisfied in conflict situations of this sort, the fairest thing that could possibly be achieved would be to satisfy no claims at all.

${ }^{3}$ Regarding the Number Problem, in additional to Taurek's claim, there are four different approaches to understanding the normative role of numbers in conflict situations. Some philosophers argue that numbers should fully count. See Parfit (1978), Kavka (1979), Kamm (1993), Kumar (1999), Scanlon (1998), Hirose (2001), Lang (2005), Rasmussen (2012), and Cohen (2014). Other philosophers argue that numbers partly count. See Kamm (1985), Timmermann (2004), and Saunders (2009). The third approach deems the policy of saving the many to be permissible, although no one is under an obligation to save the many. If the agent choose to save the few, the members of the large group cannot complain that they are being treated wrongly. See Anscombe (1967) and Munoz-Dardé (2005). The fourth approach, as a mixed opinion, argues that the majority should be saved in certain situations, while a random selection procedure should be employed to decide what to do in the other conflict situations. See Broome (1990), Hirose (2004), Lawlor (2006), Peterson (2009), Thomas (2012), and Woollard (2014).

${ }^{4}$ In Morality, Mortality Vol. I: Death and Whom to Save from It, the Best Outcome Argument is initially called "the Aggregation Argument." Although its original name might give readers the impression that the argument resorts to the aggregation of the claims on both opposing sides, it is not the case that Kamm takes the notion of aggregation as a key to the success of her argument. It is noteworthy that Kamm (2007) herself dubs it "the Argument for Best Outcome."in Intricate Ethics: Rights, Responsibilities, and Permissible Harm. The Best Outcome Argument is criticized by Timmermann (2004), Lübbe (2008), Doggett (2013), and Lee (2017). Timmermann argues that Kamm's argument doesn't pays due attention to the separateness of individuals involved, and that the best way to solve the Number Problem is to run an individualist lottery to give each person an equal chance of being saved. Given the fact that the agent responsible for the task of rescuing is under a moral obligation to save people as possible as she can, this procedure is practically, but not philosophically, equivalent to a weighted lottery. Lübbe argues that the Aggregation Argument is flawed because the moral evaluation of states of affairs cannot be considered as a ranking of items, the value of which is independent of what happens to other items. Doggett argues that it is fair to save the few in conflict cases like the Rescue Case, because it has each like person make a like difference to what is permissible. Lee argues that the Best Outcome Argument's application of Pareto and impartiality is not necessary for concluding that it is right to rescue the larger group.
} 
Pareto improvement: Pareto improvement is an improvement to a system consisting of morally relevant factors when at least one individual becomes better off without anyone becoming worse off. That means, one option is better than another, if the former is better for at least one individual and no worse for anyone than the latter.

The impartiality principle: Other things being equal, the options regarding the selection of the potential receipt of a good cannot be differentiated from one another if their only difference lies in the identities of persons. ${ }^{5}$

Firstly, Pareto improvement responds positively to multiple morally relevant factors such as well-being, happiness, preference-satisfaction, and so on. Any evaluative difference between allocation plans should be traced back to differences in morally relevant factors that each plan will honor. To illustrate, compare $M=(2,5)$ and $\mathrm{N}=(2,4)$, where the brackets of the two options show the level of well-being for person 1 and person 2 respectively. Pareto improvement would support the evaluative judgment that $\mathrm{M}$ is better than $\mathrm{N}$, since the improvement of person 2's wellbeing is an increase in the value of the set of morally relevant factors and should be taken into account seriously in the evaluation of the goodness of states of affairs. For the Rescue Case, saving both $\mathrm{B}$ and $\mathrm{C}$ is better for $\mathrm{C}$ than saving $\mathrm{B}$ alone, and it is not worse for $\mathrm{B}$, then it is better than saving $\mathrm{B}$ alone. It is easy to see that, based on Pareto improvement, it is worse if both $\mathrm{B}$ and $\mathrm{C}$ die than if $\mathrm{B}$ alone dies. That means the state consisting of the deaths of $\mathrm{B}$ and $\mathrm{C}$ is strictly worse than the state consisting of the death of B alone.

Secondly, the impartiality principle neglects all differences between persons except the strengths of their claims (or conditions). Specifically, impartiality demands that the agent responsible for allocating the good among equally situated persons is not allowed to favor any particular person except insofar as legitimate reasons so require. In terms of goodness, impartiality holds that two options are equally good if they differ only in the names given to individuals involved (call it the symmetry feature). Suppose the choice in question is between $\mathbf{M}^{*}=(2,5)$ and $\mathrm{N}^{*}=(5$, 2 ). The only difference between $\mathrm{M}^{*}$ and $\mathrm{N}^{*}$ is that person 1's well-being and person 2's well-being are shifted with respect to each other so that there is no increase or decrease in the value of the set of that morally relevant factor. Other things being constant, there seems to be no good reason, from the point of view of impartiality, to favor any specific option or any particular person. For the Rescue Case, the impartiality principle would imply that it is as bad for A to die as for B to die, since the potential loss to each person is exactly same as each other.

It follows from these two premises that the deaths of $\mathrm{B}$ and $\mathrm{C}$ is worse than the death of A alone, and generally that it is worse if more people die than fewer. Both Pareto improvement and the impartiality principle allegedly refrain from any

\footnotetext{
${ }^{5}$ It is controversial as to the nature of impartiality. Many philosophers, notably Parfit (1978) and Peterson (2010), believe that, other things being equal, impartiality demands that equally situated persons should be treated equally, and that no person counts for more than another. Hirose (2014) suggests a stronger notion of impartiality. He believes that the core of impartiality is that permutations of personal identities don't affect evaluations of states of affairs. On this matter, I follow Hirose's use of impartiality, and believe that this definition can better capture the basic idea of impartiality.
} 
commitment to moral aggregation, so this argument doesn't explicitly or implicitly appeal to the aggregation of individuals' claims. ${ }^{6}$ Hirose (2001), as a defender of the Best Outcome Argument, formally reconstructs it as follows:

$$
\begin{aligned}
& \mathrm{X}:=(\mathrm{A} \text { alive, } \mathrm{B} \text { dead, } \mathrm{C} \text { dead }) \\
& \mathrm{Y}:=(\mathrm{A} \text { dead, } \mathrm{B} \text { alive, } \mathrm{C} \text { dead }) \\
& \mathrm{Z}:=(\mathrm{A} \text { dead, } \mathrm{B} \text { alive, } \mathrm{C} \text { alive })
\end{aligned}
$$

Pareto improvement implies that $\mathrm{Y}$ is worse than $\mathrm{Z}$. The impartiality principle implies that $\mathrm{X}$ is as bad as $\mathrm{Y}$. It is concluded that $\mathrm{X}$ is worse than $\mathrm{Z}$. It is a moral shortcoming to prefer what is in itself a worse thing, and $\mathrm{X}$ is admittedly worse than $\mathrm{Z}$, so it is a moral shortcoming not to prefer $\mathrm{Z}$ to $\mathrm{X}$. It is worth noting that Pareto and the impartiality principle are represented as general principles of moral evaluation and practice. They are expected to hold in all situations, and the fact that they don't apply in some situations should not be confused as limiting its generality.

There may be two ways to undermine the Best Outcome Argument. One is to dispute the truth of either premise. The other is to deny that the conclusion follows from the premises. However, neither of these approaches is fully satisfactory. First, both Pareto improvement and impartiality principle are two intuitively plausible moral principles that are widely accepted by many philosophers. It is extremely difficult to establish that these principles are not as plausible as they may appear. Second, the conclusion of the argument seems to be a logical consequence of the premises. Very few would deny that the conclusion, namely that $\mathrm{X}$ is worse than $\mathrm{Z}$, can be properly drawn from its two premises. ${ }^{7}$ In addition to these two approaches, a third approach, which I will discuss in more detail below, aims to reveal an inherent inconsistency between the argument's assumptions about morally relevant factors.

I argue that either the first premise or the second premise is false, because the assumption of the first premise about morally relevant factors is inconsistent with that of the second premise. Specifically, in Section 2, I argue that the symmetry feature defined by the impartiality principle holds only in a limited class of conflict cases. It doesn't necessarily apply to the typical case that the Best Outcome Argument considers. In Section 3, I argue that the Best Outcome Argument should treat individuals in a consistent way throughout the whole process of reasoning. In Section 4, I argue that comparative evaluations gained in different contexts at least in some cases cannot be used in one and the same argument.

\section{The First Response: Morally Relevant Factors}

The first worry to the Best Outcome Argument is that the symmetry feature defined by the impartiality principle holds only in a narrow class of conflict cases. The Best Outcome Argument may be applied to the cases where the agent is asked to make

\footnotetext{
${ }^{6}$ Pareto and Impartiality are the essential properties of aggregation, but the combination of Pareto and Impartiality doesn't itself entail aggregation.

7 The inference from the two premises to the conclusion, namely, that it would be wrong to choose to bring out $\mathrm{X}$ rather than bring about $\mathrm{Z}$ when faced with a choice between the two, is less airtight. It relies on other normative assumptions about the connection between wrongness and value that pave the way for reaching this conclusion.
} 
life-saving decisions between two equally situated persons, but it doesn't mean that it can be safely applied to all other cases where more individuals are involved. This is partly because in many cases a conclusion that follows from premises in which the assumptions about morally relevant factors are not identical may not be right.

To illustrate, compare $\mathrm{L}=($ dead, alive, dead) and $\mathrm{O}=$ (alive, dead, dead), where the brackets show the conditions for person 1, person 2 and person 3 respectively. These two options differ only with regard to the names given to individuals. Thus, the symmetry feature will be indifferent between $\mathrm{L}$ and $\mathrm{O}$ in the comparative evaluation. However, this evaluative indifference may be considered inaccurate if it is assumed that person 3 could hypothetically be saved with person 2 without incurring too much cost, and it can be said that $\mathrm{E}=$ (dead, alive, alive) is better than $\mathrm{L}=(\mathrm{dead}$, alive, dead). When individuals' lives are at stake, only person 2's life being saved seems to mean that person 3's life doesn't count as a morally relevant factor that needs to be taken into account in the evaluation of the goodness of states of affairs.

To see the point of morally relevant factors, let us consider a conflict situation where Ross, a young man with a blind left eye, is presented with a choice between the following two options:

D1: suffering a blind right eye

D2: suffering paralyzed legs.

As far as his current heath condition is concerned, he may be indifferent between these two options, as losing both legs is as bad as total blindness (P1: D1=D2). ${ }^{8}$ Suppose further that, Ross' left eye will be, under some mysterious force, miraculously recovered to a near normal level if he is given an opportunity to make a slightly different choice between the following two options:

D1: suffering a blind right eye.

D3: suffering one paralyzed leg.

For the sake of argument, let us say that the inconvenience caused by losing one leg is of equal magnitude to that caused by losing the sight of one eye. Given that Ross' left eye will be recovered from complete darkness if he is directed to make the choice between D1 and D3, he may be indifferent between D1 and D3 (P2: $\mathrm{D} 1=\mathrm{D} 3)$. From these two premises, it follows that, by substituting D2 for D1 on the left side of the moral equation in the second premise, Ross will be indifferent between D2 and D3 (Conclusion: D2=D3). It is a conclusion simply too distressing for many to contemplate. However, it is a conclusion difficult to avoid if this line of reasoning, similarly adopted by the Best Outcome Argument, is accepted as a valid one.

The condition of Ross' left eye is considered relevant to the evaluation of states of affairs when faced with the choice between D1 and D2. Ross would not believe that D1 is indifferent to D2, unless the condition of his left eye is taken into account seriously. However, when it comes to the choice between D1 and D3, the condition of

\footnotetext{
${ }^{8}$ Some might object that losing both legs is generally not comparable to total blindness. A world without sight and color may be worse than a world in which everything is dependent on a wheelchair. But I believe this is only a harmless hypothesis.
} 
his left eye becomes irrelevant to the evaluation of states of affairs. This is because, in comparison with other sufferings, the small inconvenience caused by the condition of his left eye is so minute that it hardly make any difference to the evaluation of the states of affairs. Thus, it is easy to check that there is a significant change in the contexts whereby the evaluation of states of affairs is conducted to respond to individuals' well-being. The condition of Ross' left eye is deemed relevant in one context but not in another. The conclusion that follows from these two premises in which the assumptions about morally relevant factors are not identical might not be right. It seems to be a problem that is particularly acute for the supporters of the Best Outcome Argument.

To illustrate the problem with the Best Outcome Argument, let " $Y<Z$ " denote that it is better if both $\mathrm{B}$ and $\mathrm{C}$ are saved than if $\mathrm{B}$ alone is saved. Let "Y $=\mathrm{X}$ " denote that the world where A is saved is as good as the world where B is saved. (The Best Outcome Argument works in the following way. $\mathrm{P} 1$ : $\mathrm{Y}<\mathrm{Z}$; $\mathrm{P} 2$ : $\mathrm{X}=\mathrm{Y}$; Conclusion: $\mathrm{X}<\mathrm{Z}$.) For the sake of argument, suppose the first premise (i.e. $\mathrm{Y}<\mathrm{Z}$ ) is true. This supposition implies that $\mathrm{C}$ 's well-being is a morally relevant factor in moral evaluation. For if C's well-being is simply assumed to be morally irrelevant, it would be permissible for the agent to be morally indifferent between $(a)$ saving B \& C and $(b)$ saving only B while letting C die. Pareto improvement, in fact, considers C's well-being as seriously as it does B's well-being. So, it must be the case that the first premise deems C's well-being to be a morally relevant factor.

The second premise (i.e. $\mathrm{Y}=\mathrm{X}$ ) holds that, according to the Impartiality Principle, saving B is as good as saving A. C's situation on both sides of the moral equation is equally imperiled. It seems to imply that C's well-being is assumed to be a morally irrelevant factor in evaluating states of affairs. First, if C's life could have been saved with B's, and especially if doing so costs nothing, then $\mathrm{Y}$ is flawed in a way that $\mathrm{X}$ is not. From the perspective of Pareto improvement, $\mathrm{X}$ and $\mathrm{Y}$ are not equal, for one is Pareto efficient and the other is not. To judge them equal is to judge that C's well-being doesn't matter. If C's well-being is considered morally relevant to the evaluation of states of affairs, then $\mathrm{Y}=\mathrm{X}$ cannot be a right claim.

Second, more importantly, the claim $\mathrm{Y}=\mathrm{X}$ violates the requirement of equality. It is assumed that, as mentioned above, all individuals involved are equally situated in terms of need satisfaction. Although it is a controversial concept, with a history marked by ambiguities, the idea of equality is invariably linked to what we mean by saying that equals should be treated equally. Formally speaking, we have reason to conceive of moral agents as equal individuals at least in the minimum sense that human beings can reasonably consider them to be the kind of entities that can acknowledge the principle of equality in their value system. In conflict cases where it is impossible to satisfy all equals, equality demands either that each individual should at least be given an equal chance of satisfaction, or that the good in question should be allocated to the majority, depending on what kinds of principles of equality we obey in the theory of justice. Justice will tolerate this kind of inequality in outcome, even though it turns out that some get ventilator therapy and others don't. ${ }^{9}$

\footnotetext{
9 Broome (1990) argues that equality (or fairness), of course, may not be the only moral value that should be taken into account seriously, and its importance may sometimes be outweighed by other moral considerations that aim to maximize the satisfaction of claims, depending on how important it is for equality to prevail in certain circumstances.
} 
However, it doesn't mean that the agent is permissible not to take C's well-being into account with regard to the comparative evaluation of states of affairs. To say $\mathrm{Y}$ is indifferent to $\mathrm{X}$ is to acknowledge that $\mathrm{C}$ is not an equal among equals.

Imagine what you would say about $\mathrm{Y}=\mathrm{X}$ if $\mathrm{C}$ is asked to accept the idea that her life doesn't count in itself as a factor that would affect the evaluation of states of affairs. You might say, "Don't worry! I will save you anyway." However, it seems that $\mathrm{C}$ could reasonably reject this moral equation because she cannot make a difference to it. $\mathrm{C}$ might reply, " $\mathrm{B}$ is allowed to create a tie with A. But what is the difference between $\mathrm{B}$ and me in moral status when $\mathrm{B}$ can contribute something to the evaluation of states of affairs and I can do nothing with it? Doesn't this mean that we don't share the equal moral status?" The supporters of the Best Outcome Argument ignore the normative fact that, equals should have the same significance with regard to moral evaluation and practice. That means, if B can make a difference to the comparative evaluation, then $\mathrm{C}$, as an equal, should have the same significance on it.

\section{The Second Response: Maintaining Consistency}

The second worry to the Best Outcome Argument is that, individuals should be treated in a consistent way throughout the whole process of reasoning. Specifically, C matters when the agent is asked to consider saving $\mathrm{B}$ and $\mathrm{C}$ or saving $\mathrm{B}$ alone, but she doesn't matter when the choice in question is between saving A and the hypothetical option of saving B alone, and this inconsistency in C's mattering will actually depreciate the value of $\mathrm{Y}$ in considering the moral eq. $\mathrm{Y}=\mathrm{X}$. The symmetry feature defined by the impartiality principle holds that two options are equally good (or bad) if they differ only with regard to the names given to individuals involved. Consider a two-person case with two options $\mathrm{M}^{*}=(2,5)$ and $\mathrm{N}^{*}=(5,2)$. Other things being equal, very few can reasonably deny the claim of impartiality that the agent should be indifferent between $\mathrm{M}^{*}$ and $\mathrm{N}^{*}$.

Let us, for the sake of argument, suppose that a third person is added to the case under consideration: $\mathbf{M}^{* *}=(2,5)+(2)$ and $\mathrm{N}^{* *}=(5,2)+(2)$. It is worth noting that person 3's well-being doesn't have to be the same in both options whatever the agent chooses. On the one hand, for the hypothetical option of $\mathbf{M}^{* *}$, there exists another alternative available that is better: person 3's well-being could hypothetically be improved to 5 without incurring too much cost (i.e. $\mathbf{M}^{* * *}=(2$, $5)+(5)$ ). On the other hand, if $\mathrm{N}^{* *}$ is selected, given the conflicting features of the case, person 3 will have to share the same fate as person 2. For the evaluation of the goodness of the morally relevant factors in this three-person case, to say $\mathbf{M}^{* *}$ is indifferent to $\mathrm{N}^{* *}$ is to acknowledge that person 3's well-being is screened out of entering into the channel of the agent's comparative judgment. To make a difference to the evaluation of states of affairs, each individual must be given an opportunity to present the significance of her well-being to others involved. By claiming $\mathbf{M}^{* *}$ is indifferent to $\mathrm{N}^{* *}$, person 3 seems to be deprived of such a fair opportunity. Thus, this evaluative indifference seems to imply that person 3 cannot make a difference to the comparative evaluation if person 3's well-being remains the same in both options. 
To see the effect that the presence of $\mathrm{M}^{* * *}$ will depreciate the evaluative value of $\mathrm{M}^{* *}$ in its comparison with $\mathrm{N}^{* *}$. Consider a case where Ross, as a doctor instead of as a patient, is presented with three options:

$\mathrm{K} 1$ : treat John for his lung cancer which, if not treated, will likely threaten his life.

K2: treat Joe's COVID-19 with the medicine xyz that has no obvious side effects.

K3: treat Joe's COVID-19 with the medicine $x y z^{*}$ that will seriously affect kidney function for three months.

To facilitate discussion, let us suppose that saving one from a fatal cancer is as important as saving another from the highest risk of COVID-19 death, even if they have totally different roots in terms of pathology. Suppose further that the side effects that Joe is suffered, if xyz* is applied, are serious, but it doesn't really threaten his life. In this case, Ross is indifferent between $\mathrm{K} 1$ and $\mathrm{K} 2$ because of their equal significance to one's health condition. (P1: K1 is indifferent to K2.) For the similar reason, Ross would be indifferent between K1 and K3. (P2: K1 is indifferent to K3.) Why is this so? When individuals' lives are both at risk and at odds with each other, they should be treated in an impartial way, either they are all satisfied, or neither is satisfied. If they cannot be equally satisfied because of scarcity of medical sources or a state of emergency, they should at least be given an equal chance of receiving treatment. In a situation such as this where individuals' lives are at risk, the side effects that Joe is going to suffer cannot be the main concern of the agent responsible for making the decision. In comparison with losing one's life, suffering serious side effects from taking $\mathrm{xyz}^{*}$ doesn't appear to be as great as expected. It follows that $\mathrm{K} 2$ is morally indifferent to $\mathrm{K} 3$. (Conclusion: $\mathrm{K} 2$ is indifferent to $\mathrm{K} 3$.) However, very few would likely embrace this unwelcome conclusion.

It may be thought that if $\mathrm{K} 2$ is recognized as an available option, it is no longer the case that $\mathrm{K} 1$ is morally indifferent to K3. According to this view, Ross might be indifferent between $\mathrm{K} 1$ and $\mathrm{K} 2$, but he should not be indifferent between $\mathrm{K} 1$ and $\mathrm{K} 3$. This is because $\mathrm{K} 2$ is obviously better than $\mathrm{K} 3$, and the presence of $\mathrm{K} 2$ will depreciate the value of $\mathrm{K} 3$ in the evaluation of states of affairs. That means K3 is, in fact, inferior to K1 when Joe can be treated with xyz without incurring serious side effects. If $\mathrm{K} 1$ is not morally indifferent to $\mathrm{K} 3$, then the conclusion cannot possibly be true. This line of reasoning threatens to undermine the Best Outcome Argument that is used to argue against Taurek' claim regarding the normative role of numbers.

For the conflict situation where A and B are the only individuals competing for ventilation therapy, very few would deny that the world in which $\mathrm{A}$ is saved is as good as the world in which B is saved. However, adding a third individual (C) to either side is expected to make a difference to the comparative evaluation of states of affairs. This requirement is derived from the simple fact that whether $\mathrm{C}$ can be saved or not is not the kind of thing that is entirely out of control. When B and C could have been saved in one fell swoop without incurring too much cost, saving only B is likely to make Y less valuable than it would otherwise be. That means that the presence of C's death will depreciate the value of $Y$ in the evaluation of states of affairs. It is worth noting that I am not arguing that the claim $\mathrm{Y}=\mathrm{X}$ is false. Instead, I try 
to argue that $\mathrm{Y}=\mathrm{X}$ is right only if it assumes that C's death doesn't matter in moral deliberation.

Some might argue that, in virtue of the context sensitivity of moral irrelevance, it is compatible with the first premise that C's death is deemed morally irrelevant in the second premise. Even though the second premise assumes that C's death is a morally irrelevant factor, it doesn't mean that there is any inconsistency between these two premises. However, this approach will make the Best Outcome Argument problematic. The situation that the first premise considers is a typical conflict-free setting in which individuals' interests are not at odds with one another. The situation that the second premise considers, in contrast, is a conflict setting where $\mathrm{B} \& \mathrm{C}$ are competing with A for ventilation therapy. It is not clear "whether comparative evaluations gained in different contexts can be used in one and the same argument."10

\section{The Third Response: Comparative Evaluations in Different Contexts}

The third worry to the Best Outcome Argument is that comparative evaluations gained in different contexts, at least in some cases, cannot be used in one and the same argument. To illustrate the difficulties associated with comparative evaluations conducted in different contexts, let us consider a conflict situation where a set of options are available to the agent responsible for making the decision between individuals with different health conditions:

O1: save Mike having a cold from the threat of complete paralysis.

O2: save blind Joe from breaking a leg.

O3: save John suffering a terminal cancer from breaking a leg.

Suppose the distribution of scarce medical resources is guided by the intuition that the worst off should be given priority. According to this view, benefiting people is more important the worse off the people are. With Mike's and Joe's health conditions in mind, it is easy to check that Mike's situation would be as bad as Joe's if both of them don't receive proper treatment. ${ }^{11}$ This shows that $\mathrm{O} 1$ and $\mathrm{O} 2$ cannot be distinguished from one another solely by reference to valid reasons. Thus, $\mathrm{O} 1$ is morally indifferent to $\mathrm{O} 2$. On the other hand, the situation of John is somehow worse than that of Joe since suffering a terminal cancer is generally worse than becoming blind. Justice requires weak claims not to be satisfied before strong

\footnotetext{
${ }_{10} \mathrm{I}$ am indebted to the anonymous referee for this astute observation. I am not arguing that the claim $\mathrm{Y}=\mathrm{X}$ would necessarily imply that C's death would be considered as a morally irrelevant factor in all kinds of conflict situations. The Best Outcome Argument fails only in certain types of conflict situations. Consider a situation in which three individuals (i.e., A, B, and C) are competing for a scarce ventilator that can satisfy only one single claim. In this case, the claim Y $=\mathrm{X}$ doesn't imply that C's death is morally irrelevant. This is because permutations of personal identities don't affect evaluations of states of affairs.

11 This view has one impressive hurdle to overcome: how to determine, in terms of health condition, who is "worse off". I am not arguing that Mike's situation is exactly same as Joe's. Rather I am arguing that if it is technically permissible to compare the health conditions of different individuals, it will be reasonable to believe that Mike's situation is roughly equal to that of Joe.
} 
claims. ${ }^{12}$ When both claims cannot be equally satisfied, John's claim ought to be satisfied prior to Joe's. ${ }^{13}$ That is, given the fact that John is considered as the least well off individual, $\mathrm{O} 3$ ought to be preferred over O2. Finally, it follows that O3 ought to be preferred over O1. Let us write "=" for the relation of "be morally indifferent to" and write "> " for the relation of "be preferred over." The argument considered above can be formulated as follows:

$$
\begin{aligned}
& \text { Premise (1) : } \mathrm{O} 1=\mathrm{O} 2 \\
& \text { Premise (2) : } \mathrm{O} 3>\mathrm{O} 2 \\
& \text { Conclusion : } \mathrm{O} 3>\mathrm{O} 1
\end{aligned}
$$

If it is permissible to substitute $\mathrm{O} 1$ for $\mathrm{O} 2$ on the right side of the inequality in premise (2), this line of reasoning should be accepted; that is, if these premises are true, the conclusion should be true as well. However, it is counterintuitive to say that $\mathrm{O} 3$ should be preferred over O1, since saving Mike from the threat of complete paralysis is more important than satisfying John's interest in the treatment of his leg. The main problem with this argument is that the truth of its two premises is considered to be embedded in and supported by different evaluative contexts, and this difference in evaluative contexts leads to the counterintuitive conclusion. For O2, in its comparison with O1, Joe's breaking a leg makes a difference to the comparative evaluation of states of affairs. This is because, if breaking a leg is not taken into account, then it cannot be the case that Joe's situation is as bad as Mike's. However, when it comes to the comparison between $\mathrm{O} 2$ and O3, breaking a leg doesn't make such a difference to the comparative evaluation, since, at least from the point of view of the supporters of the Best Outcome Argument, removing the part of breaking a leg from both options seems unlikely to affect the final comparative results. ${ }^{14}$ This constitutes a distinctive evaluative context for the comparison between $\mathrm{O} 2$ and $\mathrm{O} 3$. This line of reasoning is similarly adopted by Kamm in her Best Outcome Argument. However, it is not the case that comparative evaluations gained in different contexts, at least in some conflict situations, can be used in one and the same argument.

\footnotetext{
${ }^{12}$ Stone (2011) claims that impartiality imposes two constraints upon allocative processes involving justice. The first constraint can be bifurcated into two conditions that are imposed on the final outcomes resulting from allocative processes: priority and equality conditions. The priority condition demands that weak claims not be satisfied before strong claims. If x's claim is stronger than y's and y receive the good in question, then $\mathrm{x}$ must also receive it. The priority condition will be violated if $\mathrm{x}$ is denied of the good and $\mathrm{y}$ is awarded it. The equality condition demands that equal claims be treated equally. If $\mathrm{x}$ and y both have an equal claim to the good, the equality condition can be achieved only when their claims are treated alike; either they are both satisfied, or neither is satisfied. It is implied by the combination of these two conditions that one claim is allowed to be favored over another only for legitimate reasons, and the only legitimate reasons are "claims of different levels of strength."

${ }^{13}$ For Broome (1990), if claims cannot all be perfectly satisfied in conflict situations of this sort, the fairest thing that could possibly be achieved would be satisfying no claims at all. When it comes to distribution of indivisible goods in short supply, fairness requires that each claim be given a chance of receiving the good proportionate to its strength by using a lottery, which is capable of providing a sort of surrogate satisfaction for each claim. The fairness of using a lottery is thus explained by its ability to meet the basic requirement of fairness that each claim be satisfied in proportion to its strength.

${ }^{14}$ For the comparison between $\mathrm{O} 2$ and $\mathrm{O} 3$, the only thing that agent needs to consider is whether losing one's sight can be outweighed by having a terminal cancer in evaluating the strength of individuals' conditions. As discussed above, it is simply assumed that suffering a terminal cancer is generally worse than losing one's sight.
} 
Moral irrelevance is not the notion that I specifically wish to explore in this short paper. I am inclined to understand moral relevance or irrelevance in a way that is sensitive to the context on which the evaluation of states of affairs is based. For example, my preference for a low-fat vegan diet doesn't matter when the choice is between tofu soup and broccoli soup. But it will become relevant when the choice in question is between cauliflower and lobster. Similarly, someone's death, which is deemed to be morally relevant in one situation, might be deemed morally irrelevant in another. For a situation where A and B are the only individuals who are competing for ventilation therapy, it is clear that the claim $\mathrm{Y}=\mathrm{X}$ doesn't imply that C's death is a morally irrelevant factor. However, when it comes to the situation where, in addition to being able to save B, C can be saved as well, the very equation can be accused of failing to take C's death seriously by focusing on the context of distribution.

The defenders of the Best Outcome Argument might argue that the claim $\mathrm{Y}=\mathrm{X}$ doesn't commit the agent to actually saving only B when B and C can be saved together. After all, to say that " $\mathrm{X}$ is of equal value to $\mathrm{Y}$ " is one thing, and to say that "it is permissible not to save C" is quite another. The claim $Y=X$ doesn't itself imply a normative principle that can tell us the right thing to do in the conflict situation. I don't intend to challenge this view. Rather, the point I want to emphasize here is that the evaluation of states of affairs is not insensitive to the context within which it is introduced. It is sensitive to the background context where more detailed information about individuals' well-being can be obtained. For the Rescue Case, to say $\mathrm{Y}=\mathrm{X}$ is to pretend that C's well-being doesn't matter at all. C's well-being is not only related to determining the rightness and wrongness of a distribution policy, but also to assessing the nature and operation of the evaluation of states of affairs. It is the situation in which B and C can be saved together without incurring too much cost that constitutes the context to which the agent's evaluation of states of affairs responds.

The argument presented in the above paragraph seems to be related to the notion of separability or the sure-thing principle. The sure-thing principle, as an assumption of separability across states of affairs, is the claim that what happens in one state can be evaluated independently of what happens in other states. To illustrate the digest of the sure-thing principle, let us consider two comparative evaluations, each of which consists of a choice between two alternatives: the first is between $\mathrm{F}$ and $\mathrm{G}$ and the second is between $\mathrm{H}$ and $\mathrm{J} .{ }^{15}$

\footnotetext{
${ }^{15}$ I am indebted to Broome for his outline of the sure-thing principle in his outstanding work Weighing Goods: Equality, Uncertainty and Time. The crux of Broome's work is the interpersonal addition theorem, which aims to represent the general betterness relation by an expectational utility function that is the sum of expectational utility functions representing the betterness relations of individuals. The interpersonal addition theorem rests on three premises: (1) each person's betterness relation conforms to the axioms of expected utility theory; (2) the general betterness relation is coherent; and (3) the principle of personal good. The sure-thing principle (or separability) is a very basic idea that underlies each premise, either in the dimension of states of nature or of people.
} 


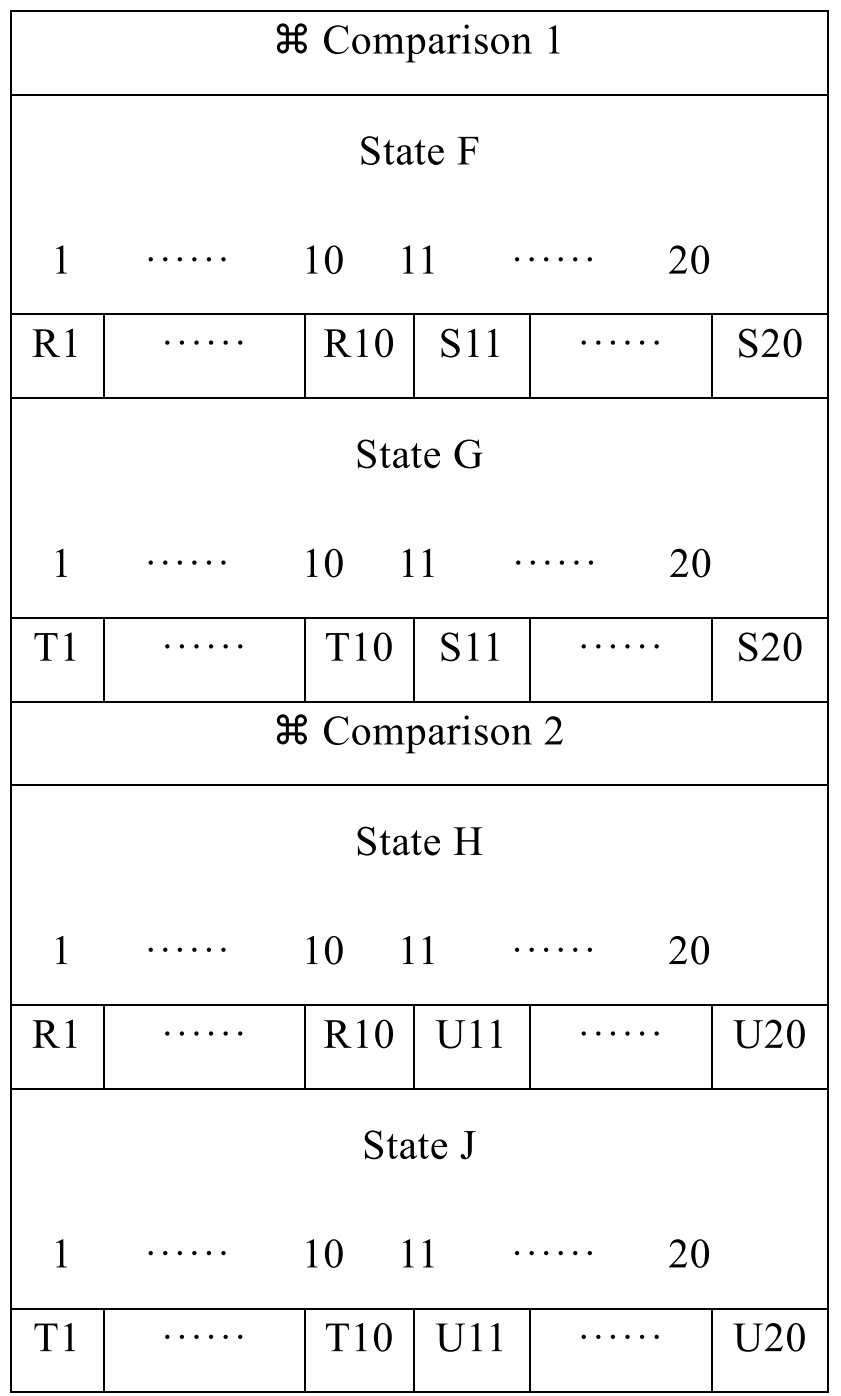

For each State, let each place in the vector indicated by numbers, 1 to 20, be a location, and Let "R"," S", "T", "U" corresponding to a specific number be what happens to each location respectively. According to the supporters of the sure-thing principle, one alternative is favored over another, if and only if the reasons for preferring the one are at least as strong as the reasons for preferring the other, and the only valid reasons come from what happens in one state or the other. For the comparison between F and G, it is easy to check that what happens in any of locations 11 to 20 is the same in $\mathrm{F}$ as that in $\mathrm{G}$. That means no reasons for preferring $\mathrm{F}$ to $\mathrm{G}$ (or for preferring $\mathrm{G}$ to $\mathrm{F}$ ) can be derived from what happens in any of locations 11 to 20 . So, what happens in locations 1 to 10 is the only places where the comparison can actually take place. The same is true for the comparison between $\mathrm{H}$ and J. Furthermore, it is also shown that, as far as the locations 1 to 10 are concerned, $\mathrm{F}$ is 
indifferent to $\mathrm{H}$, and $\mathrm{G}$ is indifferent to $\mathrm{J}$. Thus, it follows that the reasons for preferring $\mathrm{F}$ to $\mathrm{G}$ must also be the reasons for preferring $\mathrm{H}$ to $\mathrm{J}$, and vice versa. Rationality requires the agent to prefer $\mathrm{F}$ to $\mathrm{G}$, if and only if the agent prefers $\mathrm{H}$ to $\mathrm{J}$.

The problem with the sure-thing principle is that counterexamples may illustrate apparent interactions between locations, which pose a serious challenge to such a location-by-location evaluation. It is possible that people would prefer F to $\mathrm{G}$, even though it is not true that they would prefer H to J, as illustrated in the well-known "Allais Paradox". Preferring $\mathrm{F}$ to $\mathrm{G}$ and also $\mathrm{J}$ to $\mathrm{H}$ is considered rational, so it turns out that rational preference need not conform to the sure-thing principle, and to expected utility theory's axioms more generally.

The supporters of the sure-thing principle, notably Broome (1991), reply that this popular preference don't conflict with the sure-thing principle, since the outcomes of the options have not been correctly individuated to take account of feelings people may have when faced with different choices. For example, for the evaluation between $F$ and $G$, if $G$ is selected, people might deeply regret their decisions. This is because, say, selecting $\mathrm{G}$ has more risk than that of selecting $\mathrm{F}$. The agent could obtain something for sure when selecting F. But if G is selected, there is a probability that she will lose all that she could have obtained for sure in selecting F. However, when it comes to the evaluation between $\mathrm{H}$ and $\mathrm{J}$, it may not be the case that people will have the same feeling of regret for selecting either alternative. This is because, say, the potential benefits brought by either option are considered very low and nearly negligible. So the agent who would like to gamble for the chance to obtain more by, say, selecting $\mathbf{J}$ is unlikely to regret the decision, even though a slightly higher probability of receiving at least some of benefits is guaranteed by selecting H. In short, the selection in the first comparative evaluation is quite different from that in the second. As a result of it, the effects of the interactions between locations is explained by feelings that would occur in one or more of the states.

The problem with the Best Outcome Argument is the same as that with the surething principle. The basic thought underlying the sure-thing principle is that the value of a location depends only on what happens with it, and doesn't depend on how another is evaluated. That means, if some of locations are separable, then the preference for selection will be independent of outcomes in other locations. As discussed above for the Rescue Case, to say $\mathrm{Y}=\mathrm{X}$ is to acknowledge that the comparative evaluation of states is insensitive to the evaluative context on which it is based. In terms of separability, this claim can be understood that the comparative evaluation of states is insensitive to the locations that share the same occurrences or outcomes in both states. Specifically, C's situation on both sides of the moral equation (i.e. $\mathrm{Y}=\mathrm{X}$ ) is the same, and the sure-thing principle (or the notion of separability) would hold that C's situation should not affect preference for selection. Because it is assumed that C's death will occur regardless of the choice people will make.

However, there are at least two problems with this assumption. First, it is an assumption that is hardly consistent with the Best Outcome Argument's first premise, where C's outcome is not independent of the agent's choice. So it violates the logic requirement of maintaining consistency of assumptions throughout the argument. Second, it may imply that $\mathrm{C}$ cannot make a difference to the evaluation if $\mathrm{C}$ 's outcome remains 
the same on both sides of the moral equation, and as a result of it, $\mathrm{C}$ is not treated as an equal. The assumption allows for the possibility that the value of a person's life is evaluated only from a personal perspective and depends only on how this life is experienced by the person. But, the sure-thing principle (or separability) underlying this view of personal good is not yet accepted as a self-evident principle. So, in a certain sense, it can be said that it doesn't respect the moral value of equality in the distribution of good.

It is controversial as to whether Broome's reply to the difficulties raised by the Allais Paradox is successful, but this is not a concern for my analysis. Because all I want to argue is that, if this reply is persuasive, it should take into account consistency of evaluative contexts, and thus adopt the same strategy as what I follow in my argument against the Best Outcome Argument. It seems to me that Broome recognizes this point in acknowledging that the feeling of regret presented in the choice between $\mathrm{F}$ and $\mathrm{G}$ is quite different from the feeling of adventure presented in the choice between $\mathrm{H}$ and $\mathrm{J}$. The differential feelings (or, specifically, the difference in the properties of the outcomes of locations) constitute different contexts for the evaluation of states of affairs, and those heterogeneous contexts can explain why popular preferences or the effects of the interaction between locations don't actually conflict with the sure-thing principle. To put it another way, what I agree with Broome is that the evaluation of states of affairs is not insensitive to the background context where more detailed information about states or individuated outcomes can be obtained for assessment.

\section{Conclusion}

If ensuring the consistency of assumptions about morally relevant factors through all premises is a requirement for the Best Outcome Argument, then it cannot be flawless. The first premise assumes that the presence of C's well-being is a morally relevant factor, while the second premise seems to assume that it is morally irrelevant to the evaluation of states of affairs. The argument's assumptions about morally relevant factors are not consistent with one another. There may be two ways out of the predicament: either (1) we change the second premise to $\mathrm{P} 2 *$, namely, $\mathrm{B}$ lives \& $\mathrm{C}$ lives $\& \mathrm{~A}$ dies $=\mathrm{B}$ dies $\& \mathrm{C}$ dies $\& \mathrm{~A}$ lives, if we prefer sticking to the assumption of the first premise; or (2) we change the first premise to $\mathrm{P} 1 *$, namely, B lives \& $\mathrm{C}$ dies \& A dies $=\mathrm{B}$ lives $\& \mathrm{C}$ lives $\& \mathrm{~A}$ dies, if we prefer sticking to the assumption of the second premise. ${ }^{16}$ However, neither leads to the conclusion that $\mathrm{X}$ is worse than $\mathrm{Z}$.

The Best Outcome Argument fails to bring down Taurek's no worse claim. This is not because Pareto improvement and the impartiality principle themselves are in theoretical trouble, but because the assumptions of the premises, implied by these principles, cannot consistently work together. In order to criticize the Best Outcome Argument, my argument doesn't need to deny the claim that it is worse if more people die than fewer. It only needs to show that the Best Outcome Argument is subject to an unnoticed inconsistency of assumptions in the flow of reasoning.

\footnotetext{
${ }^{16}$ For (1), it is as good to save B and C as to save A. It simply shows that saving the many cannot be a moral duty. For (2), it denies the validity of Pareto and is therefore disastrous to the Best Outcomes Argument.
} 


\section{References}

Anscombe, G. E. M. (1967). Who is wronged? The Oxford Review, 5(1), 16-17.

Broome, J. (1990). Fairness. Proceedings of the Aristotelian Society, 91(1), 87-101.

Broome, J. (1991). Weighing goods: Equality, uncertainty and time. Oxford University Press.

Cohen, Y. (2014). Don't count on Taurek: Vindicating the case for the numbers counting. Res Publica, 20(3), 245-261.

Curtis, B. L. (2014). To be fair. Analysis, 74(1), 47-57.

Doggett, T. (2013). Saving the few. Nô̂s, 47(2), 302-315.

Hirose, I. (2001). Saving the greater number without combining claims. Analysis, 61(4), 341-342.

Hirose, I. (2004). Aggregation and numbers. Utilitas, 16(1), 62-79.

Hirose, I. (2014). Moral aggregation. Oxford University Press.

Kamm, F. (1985). Equal treatment and equal chances. Philosophy and Public Affairs, 14(2), 177-194.

Kamm, F. (1993). Morality, mortality Vol. I: Death and whom to save from it. Oxford University Press.

Kamm, F. (2007). Intricate ethics: Rights, responsibilities, and permissible harm. Oxford University Press.

Kavka, G. S. (1979). The numbers should count. Philosophical Studies, 36(3), 285-294.

Kumar, R. (1999). Contractualism on saving the many. Analysis, 61(2), 165-170.

Lang, G. (2005). Fairness in life and death cases. Erkenntnis, 62(3), 321-351.

Lawlor, R. (2006). Taurek, numbers and probabilities. Ethical Theory and Moral Practice, 9, 149-166.

Lee, D.-K. (2017). Against Hirose's argument for saving the greater number. Journal of Ethics and Social Philosophy, 11(2), 1-8.

Lübbe, W. (2008). Taurek's no worse claim. Philosophy and Public Affairs, 36(1), 69-85.

Munoz-Dardé, V. (2005). The distribution of numbers and the comprehensiveness of reasons. Proceedings of the Aristotelian Society, 105(2), 207-233.

Parfit, D. (1978). Innumerate ethics. Philosophy and Public Affairs, 7(4), 285-301.

Peterson, M. (2009). The mixed solution to the number problem. Journal of Moral Philosophy, 6(2), $166-177$.

Peterson, M. (2010). Can consequentialists honour the special moral status of persons? Utilitas, 22(4), 434-446.

Piller, C. (2017). Treating Broome fairly. Utilitas, 29(2), 214-238.

Rasmussen, K. (2012). Should the probabilities count? Philosophical Studies, 159(2), 205-218.

Saunders, B. (2009). A Defence of weighted lotteries in life saving cases. Ethical Theory and Moral Practice, 12(3), 279-290.

Scanlon, T. (1998). What we owe to each other. Harvard University Press.

Stone, P. (2011). The luck of the draw: The role of lotteries in decision making. Oxford University Press.

Taurek, J. (1977). Should the numbers count? Philosophy and Public Affairs, 6(4), 293-316.

Thomas, A. (2012). Giving each person her due: Taurek cases and non-comparative justice. Ethical Theory and Moral Practice, 15(5), 661-676.

Timmermann, J. (2004). The individualist lottery: How people count, but not their numbers. Analysis, 64(2), 106-112.

Woollard, F. (2014). The new problem of numbers in morality. Ethical Theory and Moral Practice, 17(4), 631-641.

Publisher's Note Springer Nature remains neutral with regard to jurisdictional claims in published maps and institutional affiliations. 